\title{
Progression of squamous cell carcinoma of the head and neck is associated with down-regulation of the opioid growth factor receptor
}

\author{
PATRICIA J. McLAUGHLIN and IAN S.ZAGON \\ Department of Neural and Behavioral Sciences, The Milton S. Hershey Medical Center, \\ The Pennsylvania State University, Hershey, PA, USA \\ Received January 10, 2006; Accepted February 20, 2006
}

\begin{abstract}
Opioid growth factor (OGF) is a native opioid peptide ([Met $\left.{ }^{5}\right]$-enkephalin) that interacts with the OGF receptor (OGFr). OGF serves as a tonically active negative growth factor in neoplasia, and the OGF-OGFr axis contributes to the maintenance of an equilibrium in cell proliferation by targeting the cyclin-dependent inhibitory kinase pathway. To inquire whether the expression of OGFr is related to tumor progression, cell lines of human squamous cell carcinoma of the head and neck (SCCHN) were transplanted into nude mice, and small, medium, and large tumors were assessed for OGFr by receptor binding assays and quantitative immunohistochemistry, and for gene expression of OGFr mRNA. Large tumors had a reduction of 3- to 7-fold in OGFr binding sites relative to small tumors, and medium size tumors showed a progressive diminishment in OGF receptors that ranged between that of small and large neoplasias. Tumors with xenografts of three different cell lines of SCCHN, representing poorly- and well-differentiated cancers, exhibited similar results. Quantitative densitometric immunohistochemistry revealed data comparable to receptor binding assays. Receptor affinity and the gene expression of OGFr mRNA were unchanged in tumors of different sizes. These data demonstrate that OGFr is reduced in SCCHN with tumor progression and that translation/ posttranslation of OGFr protein, but not transcriptional levels of the OGFr gene, is (are) involved. The attenuated levels of OGFr binding capacity may serve as a marker of SCCHN. These subnormal levels of OGFr may diminish the efficacy of the OGF-OGFr axis in maintaining cell proliferative activity, and contribute to more active cell replication. Gene therapy to
\end{abstract}

Correspondence to: Dr Patricia J. McLaughlin, Department of Neural \& Behavioral Sciences, H109, The Penn State University College of Medicine, 500 University Drive, Room C3727, Hershey, PA 17033, USA

E-mail: pxm9@psu.edu

Key words: opioid growth factor receptor, squamous cell carcinoma of the head and neck, receptors, tumor progression, biomarker, opioids reinstate more OGFr, and thus enhance OGFr function, could serve as a useful treatment for inhibiting tumor progression.

\section{Introduction}

The opioid growth factor (OGF) ([Met $\left.{ }^{5}\right]$-enkephalin) and its receptor, OGFr, have been well documented in the regulation of growth of a variety of human cancer cells in culture (1-5) and tumors in nude mice (6-9). OGF serves as an autocrineproduced, endogenous pentapeptide that inhibits cell proliferation in a receptor-mediated manner $(1-5,10)$. OGF activity is not related to apoptosis/necrosis (11) or differentiation (12), and acts in an anchorage-independent manner (13). The mechanism of action appears to be that OGF upregulates the cyclindependent kinase inhibitor pathway in order to delay the $\mathrm{G}_{0} / \mathrm{G}_{1}$ phase of the cell cycle (14). OGF and OGFr have been demonstrated by immunohistochemistry, radioimmunoassay, and/or receptor binding to be present in a variety of human and animal tumors and cancer cell lines (1-5,8,15-19).

With respect to human squamous cell carcinoma of the head and neck (SCCHN), the OGF-OGFr axis has been shown to be present (4,7,16-19) and functional $(4,7,16,20,21)$. Clinical studies assessing the level of OGFr in surgical specimens of SCCHN (19) indicated that OGFr binding sites and protein levels were 9-fold and 5-fold, respectively, less in tissues of patients with SCCHN than in normal epithelium from patients undergoing uvulapalatoplasty or tonsillectomy. Tumor margins considered to be negative for pathology revealed subnormal levels of OGFr that were intermediate between SCCHN and normal epithelium. Values of OGFr mRNA, however, were similar in SCCHN, SCCHN tumor margins, and normal specimens. These data suggest that OGFr is defective in SCCHN and that translation/posttranslation of OGF protein, but not transcriptional levels of the OGFr gene, is/are involved.

The present study examined the hypothesis that progression of SCCHN is accompanied by a decrease in OGFr protein. In order to investigate tumors of a particular size with respect to OGFr binding characteristics, an animal model that employed human SCCHN cell lines transplanted into nude mice was studied. Utilizing xenografts of 3 different SCCHN cell lines representing poorly and well-differentiated cancers, tumors were collected as 'small', 'medium', and 'large' in size (i.e., diameter, weight, volume). Receptor binding assays were performed to determine binding affinity $\left(\mathrm{K}_{\mathrm{d}}\right)$ and binding 
capacity $\left(\mathrm{B}_{\max }\right)$. Immunohistochemistry, along with quantitative densitometry, ascertained the location and relative amount of OGFr in human SCCHN. Gene expression of OGFr was determined by Northern blot analysis, and quantitation was performed.

\section{Materials and methods}

Cancer cell lines. SCC-1, CAL-27, and SCC-15 human SCCHN cell lines were used in this study. SCC-1 was obtained from The University of Michigan, Cancer Research Laboratory (Dr Thomas E. Carey, Director), whereas CAL-27 and SCC-15 were purchased from the American Type Culture Collection (Manassas, VA). The SCC-1 (UM-SCC-1) cell line was derived from a well-differentiated recurrent squamous cell carcinoma in the floor of the mouth of a 73-year-old male that had received irradiation (22). CAL-27 was derived from a poorly differentiated squamous cell carcinoma from the tongue of a 56-year-old male; the patient received no treatment prior to derivation of the cell line (23). The SCC-15 cell line was derived from a well-differentiated squamous cell carcinoma of the tongue of a 55-year-old male; the patient received no treatment (24). SCC-1 and CAL-27 cells were maintained in Dulbecco's MEM (modified) media, while SCC-15 were grown in 1:1 Ham's F12 and DMEM. All media were supplemented with $10 \%$ fetal calf serum, $1.2 \%$ sodium bicarbonate, and antibiotics $(5,000 \mathrm{U} / \mathrm{ml}$ penicillin, $5 \mathrm{mg} / \mathrm{ml}$ streptomycin, $10 \mathrm{mg} / \mathrm{ml}$ neomycin). Cell cultures were maintained in a humidified atmosphere of $5 \% \mathrm{CO}_{2} / 95 \%$ air at $37^{\circ} \mathrm{C}$. The cells were harvested by trypsinization with $0.05 \%$ trypsin $/ 0.53 \mathrm{mM}$ EDTA, centrifuged, and counted with a hemacytometer. Cell viability was determined by trypan blue staining.

Tumor cell implantation, tumor growth, and tissue collection. Male 4- to 5-week old BALB/c-nu/nu nude mice, purchased from Harlan Laboratories (Indianapolis, IN), were housed in pathogen-free isolators in the Department of Comparative Medicine at the Penn State University College of Medicine. All procedures were approved by the IACUC committee of the Penn State University College of Medicine and conformed to the guidelines established by NIH. The mice were allowed at least 5 days to acclimatize prior to beginning experimentation.

Nude mice received a single subcutaneous injection into the right scapular region of the following: $2 \times 10^{6} \mathrm{SCC}-1$ cells, $2 \times 10^{6}$ CAL-27 cells, or $10^{7}$ SCC- 15 cells. For each cell line, at least 25 mice were utilized. Cell number was titrated to that which produced $100 \%$ tumors within approximately 2 weeks of cell inoculation (4,9,21,22; ATCC Product Sheet for SCC-15).

Mice were observed daily for the initial appearance of tumors. Tumors were measured twice weekly using calipers. Tumor volume was calculated using the formula, $\mathrm{w}^{2} \times 1 \times \pi / 6$, where the length is the longest dimension, and width is the dimension perpendicular to length (25). Tumors were harvested as small, medium, or large when tumor dimensions were approximately 10,20 or $40 \mathrm{~mm}$, respectively, in one diameter.

When tumors were of the appropriate size, mice were euthanized by an overdose of sodium pentobarbital. Tumors were measured, removed and weighed. Tumor tissue was either flash frozen in liquid nitrogen for receptor binding assays, frozen in isopentane chilled on dry ice for immunohisto- chemistry, or placed in guanidine isothiocyanate buffer (GIT) and stored at $-70^{\circ} \mathrm{C}$ for RNA assays. Tissues were processed within 2 weeks of collection.

Receptor binding assays. For each assay, dependent on tumor size, 1-3 tumors were sampled. For SCC-1 tumors, 15 binding assays were conducted on tumors of each size whereas, for CAL-27 and SCC-15 tumors, 4 binding assays were performed on tumors of each size. Tumor tissues were removed, washed free of blood and connective tissue, immediately frozen in liquid nitrogen, and assessed following the procedures published previously $(8,9,17,21)$. Tumors were homogenized in $0.32 \mathrm{M}$ sucrose in Tris-buffer containing protease inhibitors (Tris/all buffer). Nuclear protein homogenates were diluted with Tris/all buffer to the appropriate protein concentration and incubated at room temperature $\left(22^{\circ} \mathrm{C}\right)$ for $10 \mathrm{~min}$ to remove endogenous opioid peptides. Aliquots $(0.95 \mathrm{ml})$ of protein were incubated with $50 \mu 1$ of $\left[{ }^{3} \mathrm{H}\right]-\left[\mathrm{Met}^{5}\right]$-enkephalin (custom synthesized by Perkin-Elmer Life and Analytical Sciences, Boston, MA) and appropriate blockers. Non-specific binding was determined in the presence of $100 \mathrm{nM}$ unlabeled $\left[\mathrm{Met}^{5}\right]$-enkephalin. Duplicate tubes of homogenates were assayed for each concentration. Protein concentrations were determined using the Bio-Rad method with $\gamma$ globulin as a standard.

Immunofluorescence microscopy. To examine for the distribution and quantity of OGFr, tumor sections were fixed and permeabilized in $95 \%$ ethanol and acetone at $-20^{\circ} \mathrm{C}$, rinsed in Sorenson's phosphate-buffer (SPB), and blocked with SPB containing 3\% normal goat serum and $0.1 \%$ Triton $\mathrm{X}-100$ at room temperature for $15 \mathrm{~min}(8,18)$. A chicken polyclonal antibody to OGFr (C17), generated to a recombinant OGFr protein (Cocalico Biologicals, Reamstown, PA) and fully characterized by Zagon et al (26), was used. Antibodies were diluted (1:500) in SPB with $1 \%$ normal goat serum in $0.1 \%$ Triton $\mathrm{X}-100$, and added to sections for $18 \mathrm{~h}$ at $4^{\circ} \mathrm{C}$. Coverglasses were washed and incubated with goat antichicken IgG 488 (1:1000) (Invitrogen-Molecular Probes, Carlsbad, CA) and viewed with fluorescence microscopy. Tissues incubated with secondary antibody only served as controls.

Sections were visualized using an Olympus IX-81 inverted microscope, equipped with a Diagnostic Instruments Spot RT-KE camera. Densitometric readings reflecting time of exposure were obtained from at least 15 different fields/tumor size, and were representative of at least 2 preparations. Digital images were collected from small and large tumors, with exposure times remaining constant for that of small tumors.

Northern blot analysis of OGFr gene expression. OGFr gene expression was assessed from at least 3 independent Northern blots, with each lane representing RNA from an individual SCC-1 tumor. Total RNA was isolated from tumors by standard procedures (19). RNA was precipitated with ethanol and quantitated by UV spectrometry. Inasmuch as possible, equal amounts of total RNA were subjected to electrophoresis on $1 \%$ agarose- $2.5 \%$ formaldehyde gels. Northern blot analysis of OGFr gene expression was performed as described earlier (19). To control for differences in the amount of RNA loaded, 
Tumor Weight (g)

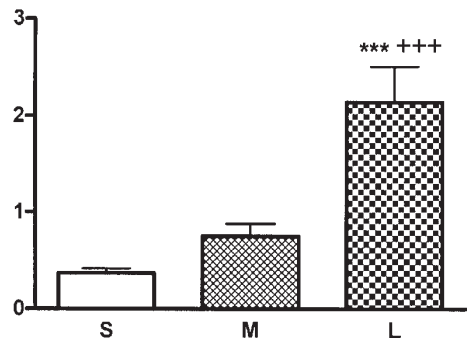

Tumor Volume $\left(\mathrm{mm}^{3}\right)$

SCC-1

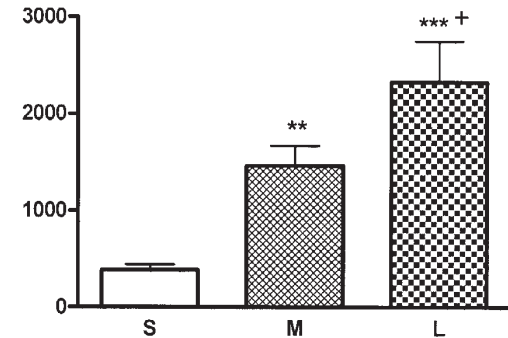

CAL-27
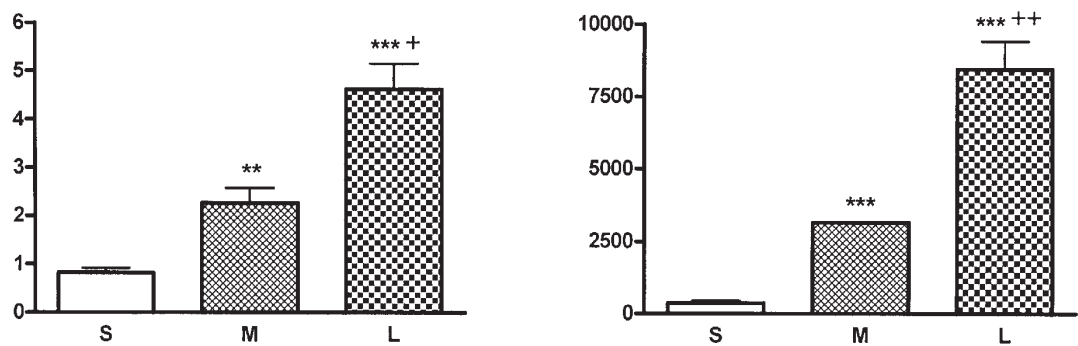

SCC-15
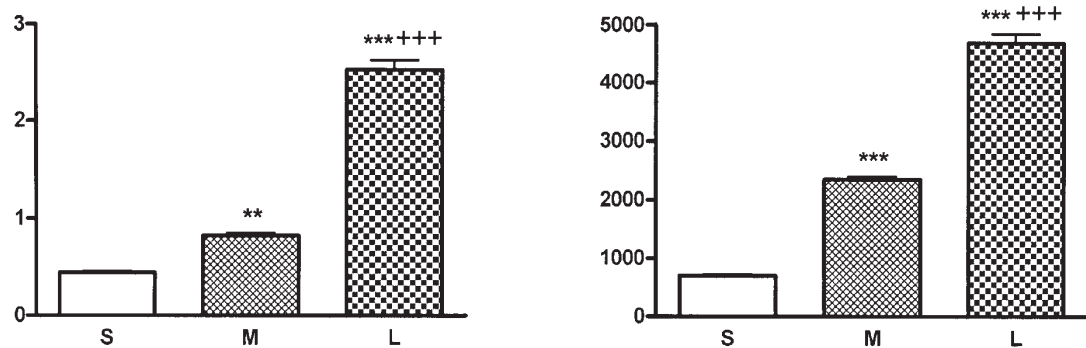

Figure 1. Tumor weight and tumor volume of small, medium, and large tumors from xenografts of SCC-1, CAL-27, or SCC-15 human SCCHN. Data represent means \pm SEM for at least 10 tumors per size. Significant difference from small tumors $\left({ }^{* *} \mathrm{p}<0.01\right.$ and $\left.{ }^{* * *} \mathrm{p}<0.001\right)$ and from medium tumors $\left({ }^{+} \mathrm{p}<0.05\right.$, ${ }^{++} \mathrm{p}<0.01$ and $\left.{ }^{+++} \mathrm{p}<0.001\right)$

as well as the integrity of the RNA, blots were stripped and reprobed with $\left.{ }^{32} \mathrm{P}\right]$-labeled cDNA for glyceraldehyde-3phosphate dehydrogenase (GAPDH).

Autoradiograms were analyzed for relative OD using a laser scanning densitometer (Molecular Dynamics/Amersham, Sunnyvale, CA) with PDQUEST software. The OD values for radiolabeled OGFr in individual blots were normalized to the OD values for GAPDH.

Data analysis. Data from binding assays were subjected to analysis with GraphPad Prism, and binding affinity $\left(\mathrm{K}_{\mathrm{d}}\right)$ and capacity $\left(\mathrm{B}_{\max }\right)$ values were generated by the computer program. Tumor weights and volumes, $\mathrm{B}_{\max }$ and $\mathrm{K}_{\mathrm{d}}$ values, and densitometric readings for gene expression, were analyzed by analysis of variance (ANOVA); subsequent planned comparisons were made with Newman-Keuls tests. Exposure times (immunofluorescent microscopy) for small and large tumors were analyzed using a 2-tailed t-test.

\section{Results}

Body weight. Athymic nude mice weighed approximately $22 \mathrm{~g}$ at the beginning of experimentation. No significant differences were noted in the body weights of mice bearing small, medium, or large tumors injected with SCC-1, CAL-27, or SCC-15 cells. Thus, at the time of termination, mice with SCC-1, CAL-27, and SCC-15 tumors had mean body weights of $26.4 \pm 0.9$, $25.5 \pm 0.8$, and $27.7 \pm 0.3 \mathrm{~g}$, respectively. 
Table I. Binding affinity of $\left[{ }^{3} \mathrm{H}\right]-\left[\mathrm{Met}^{5}\right]$-enkephalin in nuclear homogenates of human SCCHN cells xenografted into nude mice.

\begin{tabular}{lccc}
\hline & \multicolumn{3}{c}{ Tumor size } \\
\cline { 2 - 4 } Cell line & Small & Medium & Large \\
\hline SCC-1 & $3.9 \pm 1.5$ & $1.7 \pm 0.3$ & $1.7 \pm 0.3$ \\
CAL-27 & $3.4 \pm 1.1$ & $2.0 \pm 0.6$ & $1.4 \pm 0.2$ \\
SCC-15 & $4.4 \pm 1.8$ & $3.2 \pm 1.0$ & $3.1 \pm 1.0$ \\
\hline
\end{tabular}

Values represent means \pm SEM for at least 3 assays. Data did not differ between any tumor size within each cancer cell line.

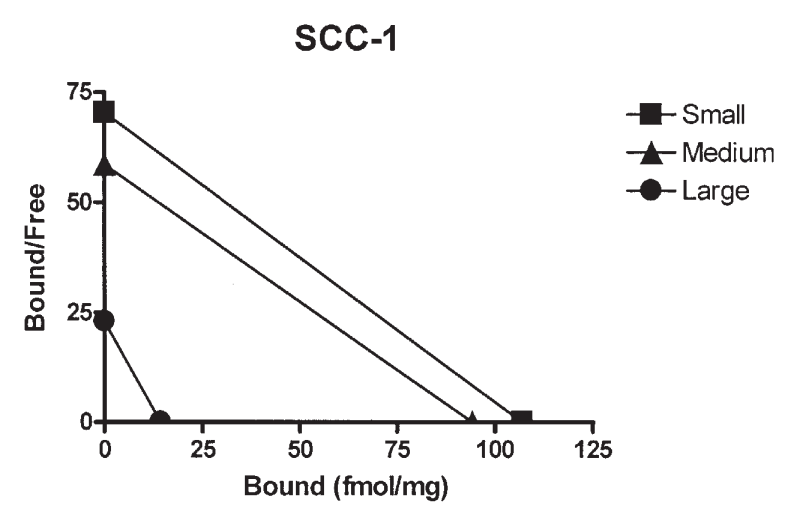

CAL-27
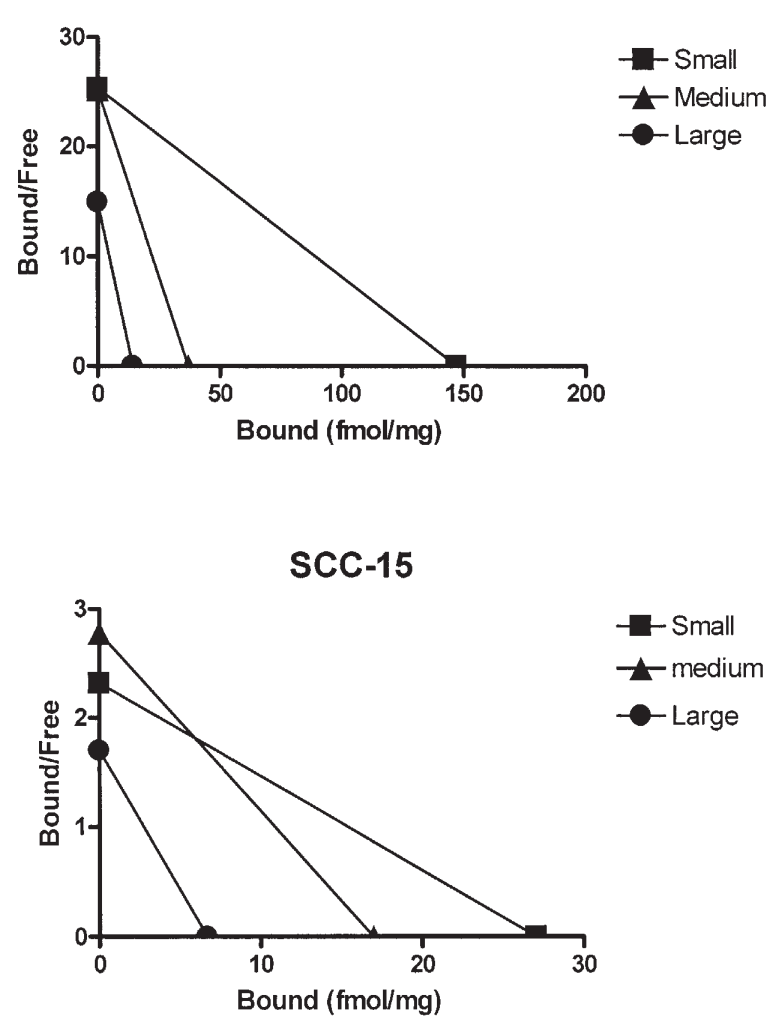

Figure 2. Representative Scatchard plots of receptor binding analyses from small, medium, and large tumors from xenografts of SCC-1, CAL-27, and SCC-15 SCCHN. Scatchard plots were generated from a single assay that approximated the mean data for the group using GraphPad Prism.

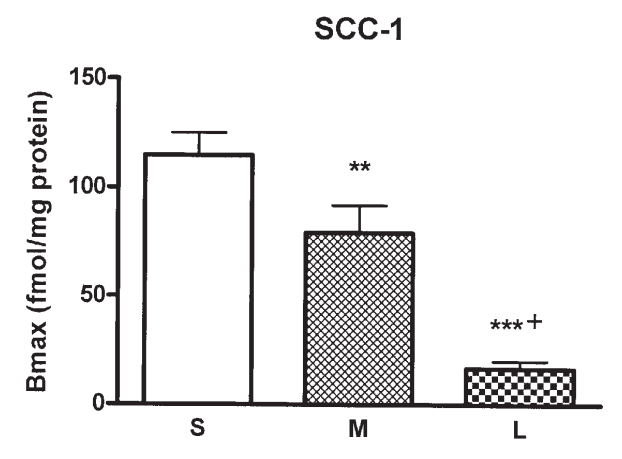

CAL 27
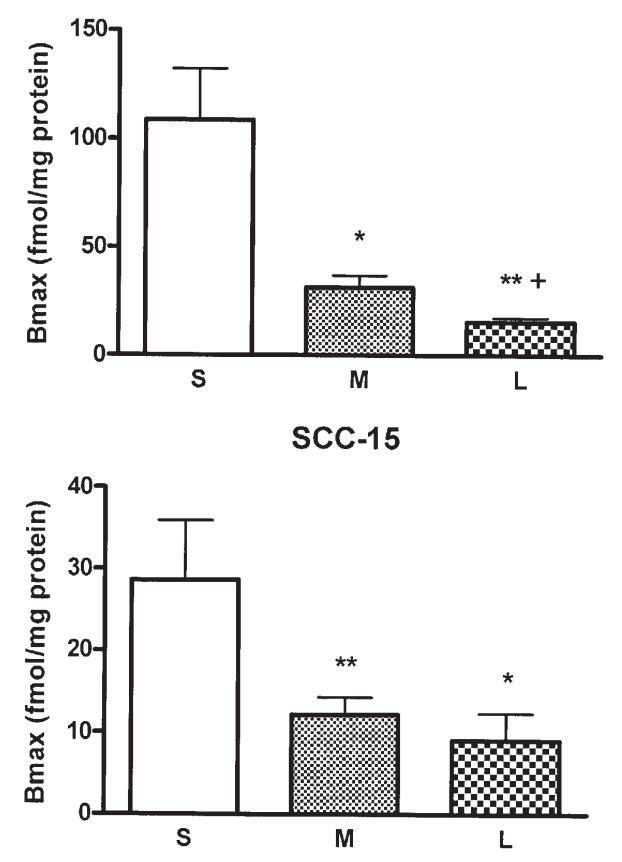

Figure 3. Binding capacity $\left(\mathrm{B}_{\max }\right)$ values for small, medium, and large tumors from SCC-1, CAL-27, and SCC-15 cells transplanted into nude mice. Histograms represent means \pm SEM for 4-15 saturation binding isotherms. Significant difference from small tumors $\left({ }^{*} \mathrm{p}<0.05,{ }^{* *} \mathrm{p}<0.01\right.$ and $\left.{ }^{* * *} \mathrm{p}<0.001\right)$ and from medium-sized tumors $\left({ }^{+} \mathrm{p}<0.05\right)$.

Tumor volume and tumor weight. Tumor weight and tumor volume of small, medium, and large tumors in mice receiving SCC-1, CAL-27, or SCC-15 cells differed significantly (Fig. 1). For example, in the SCC-1 group, the weights of medium and large size tumors were 2.0- and 5.8-fold, respectively, greater than that of the small size tumors, and the large size tumors were 2.8 -fold greater than those in the medium size group. Likewise, in the SCC-1 group, the tumor volume of medium and large size tumors was 3.8- and 6.0-fold, respectively, greater than that of small size tumors, and the large size tumors were $59 \%$ greater than those in the medium size group.

OGFr receptor binding analyses

Binding affinity. Binding affinity as measured by $\mathrm{K}_{\mathrm{d}}$ values did not differ between assays for small, medium, or large tumors in any of the SCCHN cell lines (Table I and Fig. 2).

Binding capacity. Radiolabeled OGF binding assays revealed specific and saturable binding of the ligand to OGFr with 

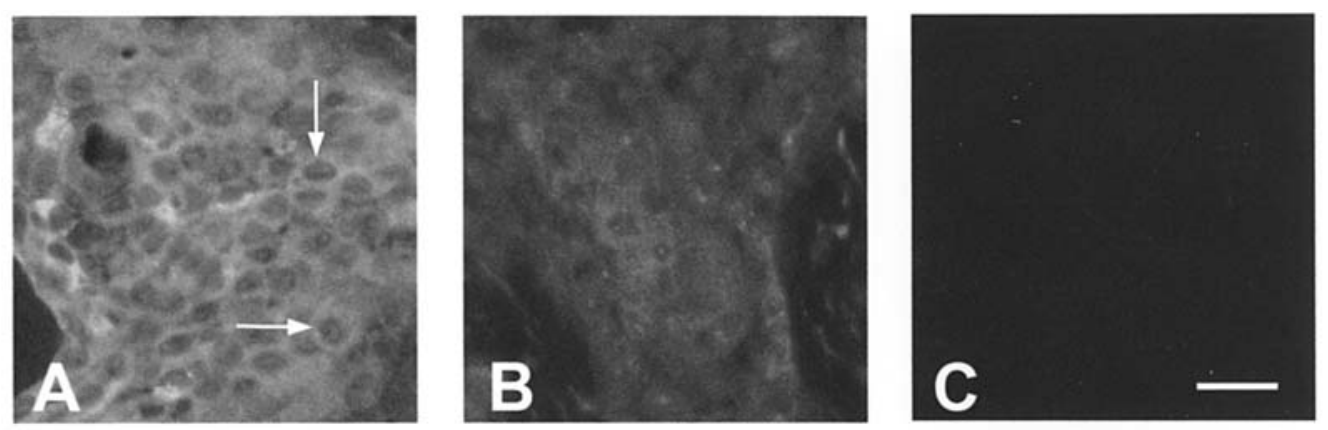

Figure 4. Immunocytochemical staining of OGFr in a small (A) and large (B) SCC-1; sections stained with secondary antibody only served as controls (C). Exposure times for all digital images were constant, and calibration was based on that for small tumors. Note intense staining of the perinuclear cytoplasm (arrows). Bar, $15 \mu \mathrm{m}$.

A

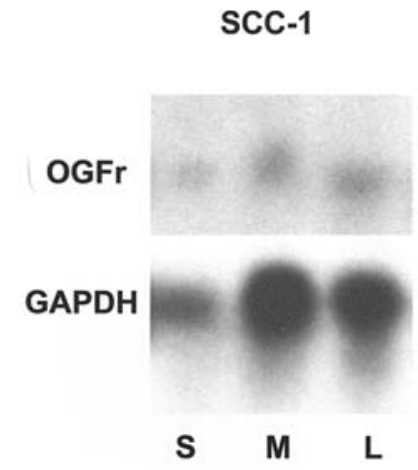

B

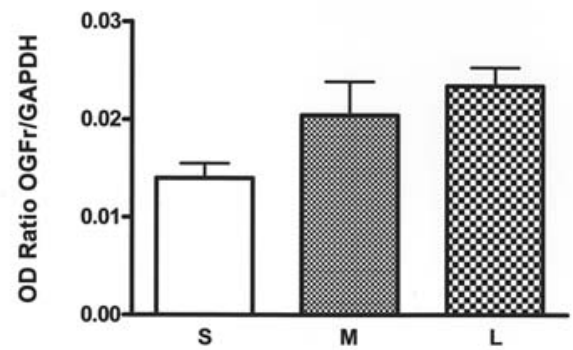

Figure 5. OGFr gene expression in specimens of small, medium, and large tumors from SCC-1 cells transplanted into nude mice. Northern blot analysis (A) of total RNA isolated from tumors probed with human OGFr cDNA; filters were stripped of isotope and reprobed with GAPDH, a constitutively expressed mRNA. Histogram of optical density ratios are presented in B. Values represent means \pm SEM. There were no statistical differences between tumors of various sizes in gene expression.

binding curves that suggested a single binding site for each of the 3 tumor cell lines examined. Values for binding capacity $\left(\mathrm{B}_{\max }\right)$ were dependent on the size of the tumor (Figs. 2 and 3). Medium and large tumors of SCC-1, CAL-27, and SCC-15 were reduced in the $\mathrm{B}_{\max }$ of OGFr by $31-86 \%$ compared to small tumors, and large tumors were reduced in the $\mathrm{B}_{\max }$ of OGFr by $26-79 \%$ compared to medium size tumors.

Immunohistochemistry of OGFr. OGFr immunolabeling was detected in the cytoplasm, and sometimes in the nucleus, of cells in small, medium, and large SCC-1 tumors (Fig. 4); no immunoreactivity was observed in sections processed with secondary antibody only. Qualitative assessment indicated that immunoreactivity appeared to be greater in cells from small tumors than in cells from large tumors. Quantitative densitometry of these sections revealed that the exposure time for small tumors $(0.86 \pm 0.04 \mathrm{sec})$ was significantly $(\mathrm{p}<0.001)$ shorter than for large tumors $(1.48 \pm 0.05 \mathrm{sec})$.

OGFr gene expression. Quantitative analysis of OGFr gene expression as measured by RNA isolated from small, medium, or large SCC-1 tumors demonstrated similar expression profiles of OGFr normalized to GAPDH independent of tumor size (Fig. 5).

\section{Discussion}

Data generated in this study demonstrate that the number of OGF receptors in SCCHN corresponds to the size and, presumably, the progression of the tumor. Comparison of large tumors that were generally 2-fold greater in diameter, weight, and volume than small tumors, revealed that large tumors had 3- to 7-fold fewer OGF receptors than small tumors. However, there were no changes in the binding affinity of these receptors, indicating that a targeted change related to OGF receptor number occurred. The decrease in OGFr number was also found to be unrelated to transcriptional activity, with no irregularities in gene expression of OGFr despite the substantial difference in receptor number between small and large tumors. The question can be raised whether the down-regulation in OGFr was specific to a particular human SCCHN cell line or if this is a more generalized observation with SCCHN. Utilization of 3 different human SCCHN cell lines demonstrated a decrease in OGFr in all 3 cell lines as tumor size increased, indicating that the inverse relationship between tumor progression and OGFr expression appears to be a consistent property of SCCHN. The present study also questioned whether the difference in OGF receptors between small and large SCCHN tumors occurred in poorlydifferentiated and well-differentiated neoplasias. Given that the binding capacity of OGFr decreased as tumor size increased with both poorly-differentiated (CAL-27) and welldifferentiated (SCC-1, SCC-15) tumors, it appears that changes in OGF receptor number with tumor progression is not dependent on the state of differentiation of the cancer. 
Thus, for the first time, our results with an animal model of human SCCHN indicate that there is a loss of OGF receptors with progression of SCCHN.

The line of inquiry taken in the present investigation is based on observations reported in a previous study (19), and confirms and explains these earlier findings. McLaughlin and colleagues (19), using tissues from 64 patients with SCCHN and from 49 patients undergoing uvulapalatoplasty or tonsillectomy, found approximately one-tenth of the OGFr binding sites in tumor tissue in comparison with normal samples. These alterations in OGFr binding were unrelated to gender or the type, stage, or differentiation status of SCCHN. OGFr protein levels, ascertained by Western blotting with antibodies to this receptor, were reduced 5-fold in tumor tissues relative to normal epithelium. However, values of OGFr mRNA were comparable in tumorigenic and normal epithelium. An intriguing observation in this earlier report was that inspections of the margins of SCCHN considered to be negative for pathology revealed subnormal levels of OGFr relative to control specimens. The authors of this study discuss the possibility that the loss of OGFr in the margins may herald a transitional state directed towards tumorigenesis, with OGFr a sensitive prognosticator of changes from normal to abnormal epithelium. Although this previous study was suggestive that OGFr number was dependent on tumor progression, it must be kept in mind that 'staging' of tumors according to size was not possible. The present report employs an animal model of human SCCHN to discern the relationship between OGFr and SCCHN progression. The results of this study are consistent with that of the previous investigation, and demonstrate that progressive neoplasia associated with SCCHN is accompanied by a loss of OGF receptors. This defect in OGFr is not reliant on transcriptional changes or the state of differentiation of the tumor. It is now understandable why previous observations (19) found a subnormal number of OGF receptors in tumor margins. In actuality, these investigations were detecting a biological process of receptor loss with the advancement of these neoplasias. Therefore, if the results of these xenograft studies can be extended to humans, a principle element in the advancement of SCCHN is a loss of OGFr.

Since OGF is a tonically active inhibitory peptide that interacts with the OGF receptor to establish an equilibrium of cell proliferation, it can be postulated that the loss of OGF receptors in SCCHN would shift the balance of cell replication towards an increase because of the attenuation of the OGFOGFr axis. This would invoke the concept of a primary participation of OGFr in the tumor process. Alternatively, the loss of OGFr with the progression of SCCHN could be secondary to other biological activities. For example, a loss of components in the synthesis of OGFr - or an increase in degradative process involved with OGFr - may be responsible for the progressive decrease in OGFr number with advancing SCCHN. Whether a diminishment of OGFr with tumor progression occurs in other types of cancers remains to be investigated.

The clinical significance of these findings is that a receptor for a native opioid peptide, which forms an endogenous opioid system that plays a role in maintaining homeostatic equilibrium in the cellular renewal of the epithelium, is compromised in advancing SCCHN. These results could be used in devising diagnostic testing of SCCHN, particularly taking advantage of the changes in the progress of tumorigenesis. For example, examination of the margins of SCCHN for OGFr, in the absence of overt pathological differences, could provide valuable insight into the status of neoplasia. Future objectives based on these data include the need to investigate the mechanism underlying the defect in OGFr in SCCHN and develop treatment strategies that prevent the loss of OGFr and/or the replacement of OGFr (e.g., gene therapy).

\section{Acknowledgements}

This research was supported by a grant from Philip Morris USA Inc. and Philip Morris International. We thank Jody Hankins and Caitlin Groff for technical assistance.

\section{References}

1. Zagon IS, Hytrek SD and McLaughlin PJ: Opioid growth factor tonically inhibits human colon cancer cell proliferation in tissue culture. Am J Physiol 271: R511-R518, 1996.

2. McLaughlin PJ, Zagon IS and Skitzki J: Human neuroblastoma cell growth in tissue culture is regulated by opioid growth factor. Int J Oncol 14: 373-380, 1999.

3. Zagon IS, Smith JP and McLaughlin PJ: Human pancreatic cancer cell proliferation in tissue culture is tonically inhibited by opioid growth factor. Int J Oncol 14: 577-584, 1999.

4. McLaughlin, PJ, Levin RJ and Zagon IS: Regulation of human head and neck squamous cell carcinoma growth in tissue culture by the opioid growth factor. Int J Oncol 14: 991-998, 1999.

5. Bisignani GJ, McLaughlin PJ, Ordille SD, Jarowenko MJ and Zagon IS: Human renal cell proliferation in tissue culture is tonically inhibited by opioid growth factor. J Urol 162: 2186-2191, 1999.

6. Zagon IS, Hytrek SD, Lang CM, Smith JP, McGarrity TJ, Wu Y and McLaughlin PJ: Opioid growth factor ([Met $\left.{ }^{5}\right]$-enkephalin) prevents the incidence and retards the growth of human colon cancer. Amer J Physiol 271: R780-R786, 1996.

7. Zagon IS, Hytrek SD, Smith JP and McLaughlin PJ: Opioid growth factor (OGF) inhibits human pancreatic cancer transplanted into nude mice. Cancer Lett 112: 167-175, 1997.

8. McLaughlin PJ, Levin RJ and Zagon IS: Opioid growth factor (OGF) inhibits the progression of human squamous cell carcinoma of the head and neck transplanted into nude mice. Cancer Lett 199: 209-217, 2003.

9. McLaughlin PJ, Stack BC, Braine KM, Ruda JD and Zagon IS: Opioid growth factor (OGF) inhibition of a human squamous cell carcinoma of the head and neck in nude mice: dependency on the route of administration. Int J Oncol 24: 227-232, 2004.

10. Zagon IS, Roesener CD, Verderame MF, Ohlsson-Wilhelm BM, Levin RJ and McLaughlin PJ: Opioid growth factor regulates the cell cycle of human neoplasias. Int J Oncol 17: 1053-1061, 2000.

11. Zagon IS and McLaughlin PJ: Opioids and the apoptotic pathway in human cancer cells. Neuropeptides 37: 79-88, 2003.

12. Zagon IS and McLaughlin PJ: Opioids and differentiation in human cancer cells. Neuropeptides 39: 495-505, 2005.

13. Zagon IS and McLaughlin PJ: Opioid growth factor (OGF) inhibits anchorage-independent growth in human cancer cells. Int J Oncol 24: 1443-1448, 2004

14. Cheng F, Zagon IS, Verderame MF and McLaughlin PJ: OGFOGFr axis and its inhibitory actions on cell cycle progression of head and neck cancer cell line SCC1. Mol Biol Cell 16: 77, 2005.

15. Hytrek SD, Smith JP, McGarrity TJ, McLaughlin PJ, Lang CM and Zagon IS: Identification and characterization of the $\zeta$-opioid receptor in human colon cancer. Am J Physiol 271: R115-R121, 1996.

16. Zagon IS, Smith JP, Conter R and McLaughlin PJ: Identification and characterization of opioid growth factor receptor in human pancreatic adenocarcinoma. Int J Mol Med 5: 77-84, 2000.

17. McLaughlin PJ, Levin RJ and Zagon IS: The opioid growth factor receptor (OGFr) in human head and neck squamous cell carcinoma. Int J Mol Med 5: 191-196, 2000. 
18. Levin RJ, Wu Y, McLaughlin PJ and Zagon IS: Expression of the opioid growth factor, [Met $\left.{ }^{5}\right]$-enkephalin, and the zeta opioid receptor in head and neck squamous cell carcinoma. Laryngoscope 107: 335-339, 1997.

19. McLaughlin PJ, Stack BC, Levin RJ, Fedok F and Zagon IS: Defects in the OGF receptor (OGFr) in human squamous cell carcinoma of the head and neck. Cancer 97: 1701-1710, 2003.

20. McLaughlin PJ, Jaglowski JR, Verderame MF, Stack BC Leure-duPree AE and Zagon IS: Enhanced growth inhibition of squamous cell carcinoma of the head and neck by combination therapy of paclitaxel and opioid growth factor. Int J Oncol 26: 809-816, 2005.

21. Jaglowski JR, Zagon IS, Stack BC, Verderame MF, LeureduPree AE, Manning JD and McLaughlin PJ: Opioid growth factor (OGF) enhances tumor growth inhibition and increases the survival of paclitaxel-treated mice with squamous cel carcinoma of the head and neck. Cancer Chemother Pharmacol 56: 97-104, 2005.

22. Krause CJ, Carey TE, Ott RW, Hurbis C, McClatchey KD and Regezi JA: Human squamous cell carcinoma. Arch Otolaryngol 107: 703-710, 1981.
23. Gioanni J, Fischel J-L, Labert J-C, Demard F, Mazeau C, Zanghellini E, Ettore F, Formento P, Chavel P, Lalanne C-M and Courdi A: Two new human tumor cell lines derived from squamous cell carcinomas of the tongue: establishment, characterization and response to cytotoxic treatment. Eur $\mathbf{J}$ Cancer Clin Oncol 24: 1445-1455, 1988.

24. Rheinwald JG and Beckett MA: Tumorigenic keratinocyte lines requiring anchorage and fibroblast support cultured from human squamous cell carcinomas. Cancer Res 41: 1657-1663, 1981.

25. Shim WSN, Teh M, Mack POP and Ge R: Inhibition of angiopoietin-1 expression in tumor cells by an antisense RNA approach inhibited xenograft tumor growth in immundeficient mice. Int J Cancer 94: 6-15, 2001.

26. Zagon IS, Ruth TB, Leure-duPree AE, Sassani JW and McLaughlin PJ: Immunoelectron microscopic localization of the opioid growth factor receptor (OGFr) and OGF in the cornea. Brain Res 967: 37-47, 2003. 